\title{
Transformation mechanism of microstructure and residual stress within hardening layer in PSHG
}

\author{
Shichao XIU* and Xiaoliang SHI* \\ *School of Mechanical Engineering and Automation,Northeastern University, \\ No. 11-3, Wenhua Road, Heping District,Shenyang, Liaoning, 110819, China. \\ E-mail: xlshi89@163.com
}

Received 21 May 2015

\begin{abstract}
The Pre-stressed Hardening Grinding (PSHG) is presented combining with the advantages of Pre-stressed Grinding and Grinding Hardening. In order to study the variation mechanism of metallographic structure and the residual stress within hardening layer under PSHG, the paper took 45 steel as the experimental object and carried on the PSHG experiment. The surface hardening layer with little residual stress was obtained from it. The surface hardness, the wear loss and residual stress were measured and its metallographic structure was observed. Combined with experimental result and the simulation of grinding temperature field, the paper studied the mechanism which the pre-stress influences the metallographic structure and the residual stress. The study shows that parent-phase-hardening and strain-inducing-phase-changing due to applying pre-stress have comprehensive effect on the martensitic phase transformation in the grinding process. And its result indicates that the pre-stress restrains the phase transformation with grinding hardening layer firstly and then promotes it. And then pre-stress affects the residual stress mainly through affecting phase transformation in the typical PSHG. It has the same variation as phase transformation with the increasing of pre-stress in the process.
\end{abstract}

Key words: Grinding-hardening, Simulation of temperature field, Pre-stress, Mechanism of phase transformation, Residual stress, Pre-stressed Hardening Grinding

\section{Introduction}

Grinding is a kind of process that utilizes abrasive grains to remove materials, and it is widely used in mechanical manufacturing industry. Pre-stressed Grinding (PSG) procedure is a kind of process which combines grinding and residual stress controlling. Though it has no process on adjusting and controlling the residual stress, the surface of specimen could produce ideal residual stress directly after grinding. So the fatigue strength of part is improved, and its working life extends (Ye, et al., 2008). Grinding Hardening (GH) takes the advantage of massive grinding heat, and the surface materials are heated quickly to the phase-transition temperature, then cools rapidly at the speed which is quicker than the critical cooling speed of martensite transformation, so martensite phase transformation appears near the surface materials and the grinding hardening occurs (Brinksmeier and Brockhoff, 1999). GH procedure combines grinding and surface hardening. It uses the grinding heat directly to carry on thermal treatment on the surface of specimen, and reduces the procedures of thermal treatment of work, the thermal treatment equipment and the staff. It reduces resources and pollution in accordance with green manufacture and the clean production pattern (Xiu, et al., 2007) (Zhang, et al., 2007) (Menenzes, et al., 2011) (Slowinski and Nadolny, 2007) (Liu, et al., 2006). Although these two technologies have their own advantages, each of them has its shortage. GH technology can't control the residual stress of surface, therefore it doesn't consider the anti-fatigue property of wokpiece. So it can't make full use of materials and obtain the longest working life. And the PSG technology can't obtain hardening layer. So the grinding heat is wasted and it is not environmental friendly.

Researchers have studied the GH technology and the PSG technology, and have got some development. But nobody has studied the area which combines the two. So the paper comes up with Pre-stressed Hardening Grinding 
(PSHG) processing method and carried on PSHG experiment based on the deep research on GH and PSG technology. It starts from anti-fatigue manufacturing and green manufacturing, and combines GH with PSG. And the surface hardening layer with little residual stress can be obtained from PSHG which has good working performance.

During the PSHG process, grinding heat leads to surface quenching and martensite phase transformation occurs. The pre-stress of the process has a great influence on the transformation mechanism of microstructure and the residual stress. By adjusting the value of pre-stress, the feature of microstructure and variation of residual stress can be controlled. Researchers home and abroad have done some researches on the stress and strain's influence on microstructure and residual stress under the condition of normal quenching, while the transformation mechanism and the variation of residual stress in the state of grinding hardening haven't been explored. So the article will analyze the typical process by combining experiment result and the theory of thermal phase transformation. The study of mechanism has instructive meaning on controlling the properties of surface hardening layer and the working performance of parts after grinding.

\section{PSHG experiment}

\subsection{Experiment Conditions}

The experiment equipment and grinding wheel is shown in Table 1.

Table 1Experiment equipment and grinding wheel

\begin{tabular}{|c|c|c|c|}
\hline Experiment equipment & Grinding wheel & Granularity of grind wheel I & Diameter of grinding wheel(mm) \\
\hline M7120A flat grinder & white corundum & F46 & 250 \\
\hline \multicolumn{4}{|c|}{$\begin{array}{r}\text { The material of the experiment is } 45 \text { steel. Its initial properties are shown in Tak } \\
\text { Table } 2 \text { Initial properties of } 45 \text { steel }\end{array}$} \\
\hline Hardness(HV) & Elasticity modulus (GPa) & Yield strength (MPa) & a) Shear modulus (GPa) \\
\hline 210 & 209 & 355 & 82 \\
\hline
\end{tabular}

The experiment specimen was processed especially. Its $\mathrm{L} \times \mathrm{W} \times \mathrm{H}$ is $50 \mathrm{~mm} \times 10 \mathrm{~mm} \times 20 \mathrm{~mm}$. The grinding width is $10 \mathrm{~mm}$. The specimen is shown in Fig.1.

The grinding hardening layer is formed by both grinding force and grinding heat. And grinding force, grinding heat and grinding parameter have a close relation. So the experiment took different grinding parameter and pre-stress and carried on grinding hardening. In order to get the temperature of austenitizing easily, the experiment took dry grinding, avoiding coolant taking away heat. The hardening effect of down-grinding is better than up-grinding, so the experiment took down-grinding. In sum, the experiment condition was determined and shown in Table 3.

\begin{tabular}{llllll}
\multicolumn{5}{c}{ Table 3 Conditions of Pre-stressed Hardening Grinding experiment $\left(v_{s}=37 \mathrm{~m} / \mathrm{s}\right)$} \\
\hline \hline No. & $a_{p}(\mu \mathrm{m})$ & $v_{w}(\mathrm{~m} / \mathrm{s})$ & Pre-torque $(\mathrm{N} \cdot \mathrm{m})$ & Grinding fluid & Grinding way \\
\hline 1 & 50 & 0.033 & 20 & & \\
2 & 50 & 0.033 & 40 & Dry grinding & Up-grinding \\
3 & 50 & 0.033 & 60 & & \\
4 & 200 & 0.022 & 20 & & \\
5 & 200 & 0.022 & 40 & & \\
6 & 200 & 0.022 & 60 & & \\
\hline
\end{tabular}

Where, $a_{p}$ is the depth of cut, $v_{s}$ is the wheel speed, $v_{w}$ is the feeding speed.

The process of the experiment is shown as Figure2. Each $a_{p}$ was achieved in single process. The specimens were cool down first and then pre-stress was unloaded after grinding. 


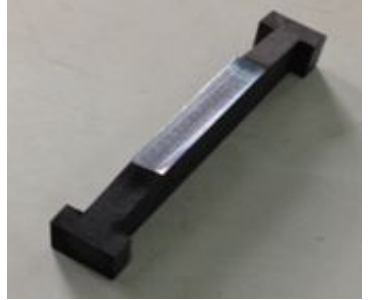

Fig.1 Figure of specimen

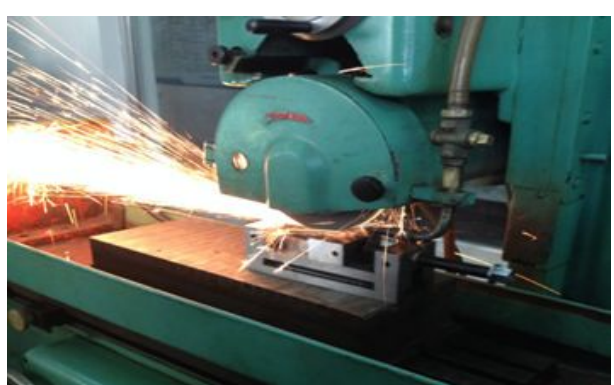

Fig.2 Experiment process of Pre-stressed Hardening Grinding

In the PSHG experiment, a special fixture was designed and made in order to apply pre-stress on both ends of workpiece before grinding. Through applying certain pre-torque by a torque wrench, it transforms it to certain pre-stress. And we calculated the transformation equation according to its structure and size. The tensile stress applied onto the specimen is:

$$
\sigma=\frac{6 M}{2 d f_{c} A+3 d_{2} A \frac{P+\pi d_{2}}{\pi d_{2}-P f}}
$$

Where, $M$ is the torque applied on the screw, $f_{c}$ is the friction coefficient between the screw and slider; $f$ is the friction coefficient between the thread, $A$ is the CSA of the specimen, $d_{2}$ is the pitch diameter of the thread, $d$ is the nominal diameter of the thread screw, $P$ is the screw pitch of the screw. $A=220 \mathrm{~mm}^{2}$, so the pre-stress equation is:

$\sigma=\frac{M}{6} \times 10^{3}$

According to Equation (2), the pre-stress is $33 \mathrm{MPa}(20 \mathrm{~N} \cdot \mathrm{m}), 66 \mathrm{MPa}(40 \mathrm{~N} \cdot \mathrm{m})$ and $100 \mathrm{MPa}(60 \mathrm{~N} \cdot \mathrm{m})$ by turn.

The principle of applying pre-stress is shown as Figure 3.

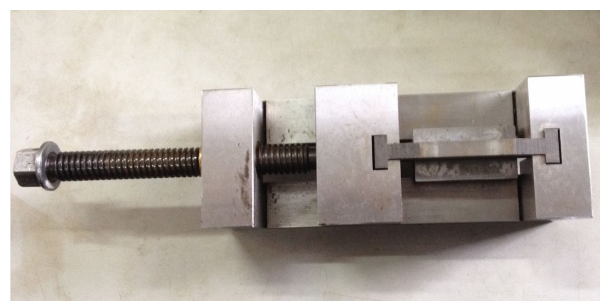

Fig.3 Pre-stress applying fixture

\subsection{Hardness Measurement Result and Analysis}

THV-5 Automatic turret Vickers hardness tester is used to measure the hardness of specimen's surface. The hardness of cut-in, middle and cut-off area is measured. Its principle is like this: the tapered diamond is pressed into materials' surface at the certain load. After some certain time, the diagonal length of impression is measured with microscope. The area of impression is calculated. Then the load divided the area is the Vickers hardness (HV). Its equation is:

$$
H V=0.012 F / S=0.102 \times \frac{2 F \sin (\alpha / 2)}{d^{2}}
$$

Where, $F$ is the load $(\mathrm{N}), S$ is the area of the impression $\left(\mathrm{mm}^{2}\right), \quad \alpha$ is the included angle of opposite side of pressure head which is $136^{\circ}, d$ is the average length of diagonal of impression ( $\mathrm{mm}$ ).

Each area has three measured values. Solve their average values, and list them in Table 4.

It can be observed that the hardness of No.1, No.2 and No.3 specimens has no obvious change and they have no hardening effect. This is because their depth of cut is small. So the pre-stress under the condition has almost no influence on the hardness of hardened layer. And it has no obvious effect on phase transformation.

And No.4, No.5 and No.6 specimens all have obvious hardening effect. The three groups belong to the typical PSHG. Their hardness shows the variation tendency of big-small-big with the pre-stress varying from small to big. 


\begin{tabular}{|c|c|c|c|}
\hline No. & Cut-in area & Middle area & Cut-off area \\
\hline 1 & 223.9 & 243.7 & 233.7 \\
\hline 2 & 248.8 & 247.4 & 239.9 \\
\hline 3 & 221.4 & 259.2 & 239.1 \\
\hline 4 & 716.1 & 787.3 & 703.3 \\
\hline 5 & 551.0 & 630.4 & 682.1 \\
\hline 6 & 681.6 & 647.8 & 787.9 \\
\hline
\end{tabular}

\subsection{Microstructure Result and Initial Analysis}

The metallographical micrographs of No.4, No.5 and No.6were observed with OLYMPUS GX71 inverted metalloscope which is a common observation method in the study of phase transformation.

Before observation, the specimens were coped with lapping, polishing, cleaning and chemical attack.

Figure 4 (a), Figure 5 (a) and Figure 6 (a) are the metallographical micrographs enlarged 50 times of No.4, No.5 and No.6 specimen, and Figure 4 (b), Figure 5 (b) and Figure 6 (b) are their metallographical micrographs of hardening layer enlarged 500 times. Their surface microstructure can be divided into 3 areas: the fully hardening layer, the transition layer and matrix. The fully hardening layer consists of martensite, also a little ferrite and troostite around it. The transition layer consists of the mixture of martensite and ferrite. The matrix consists of ferrite and pearlite.

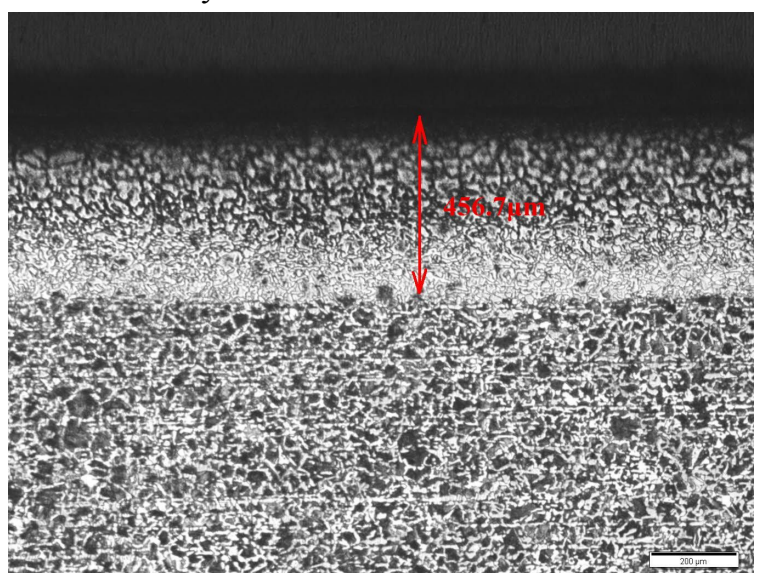

(a)

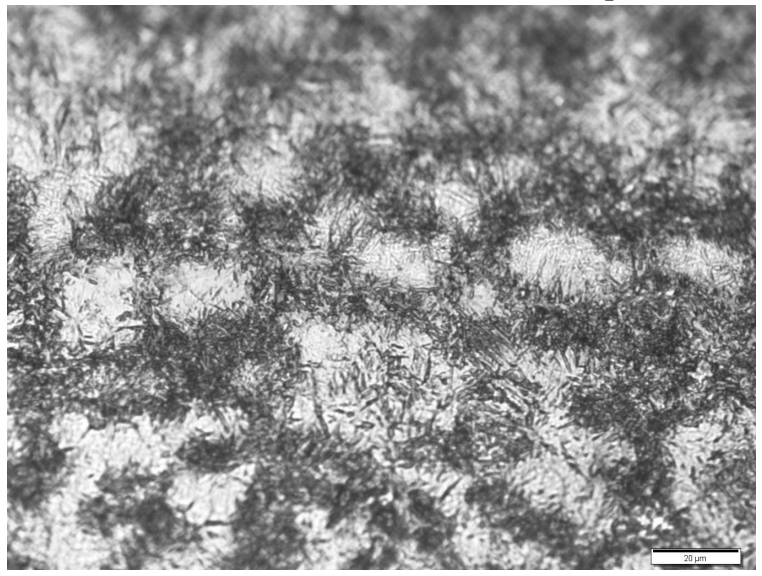

(b)

Fig.4 Metallographical micrograph of No.4 specimen

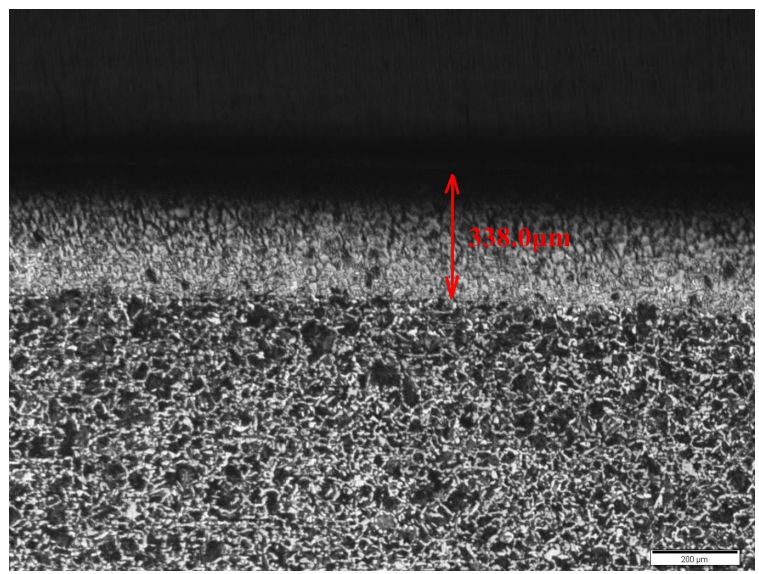

(a)

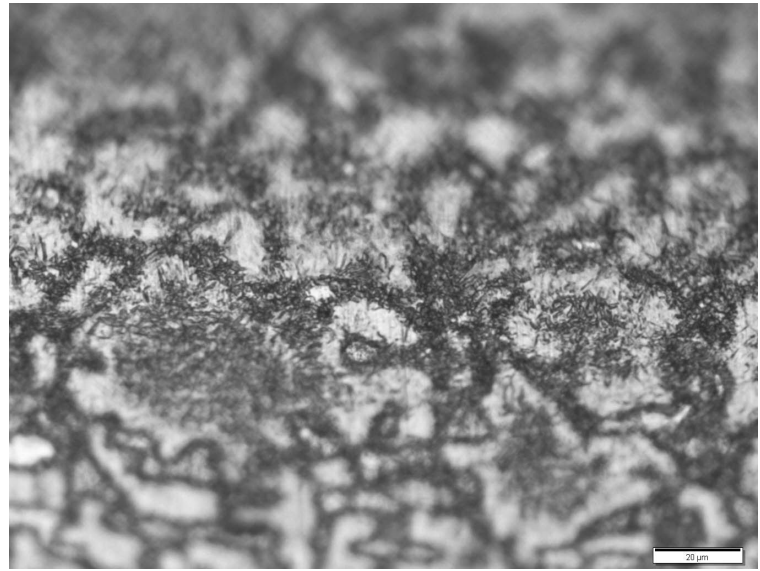

(b)

Fig.5 Metallographical micrograph of No.5 specimen 


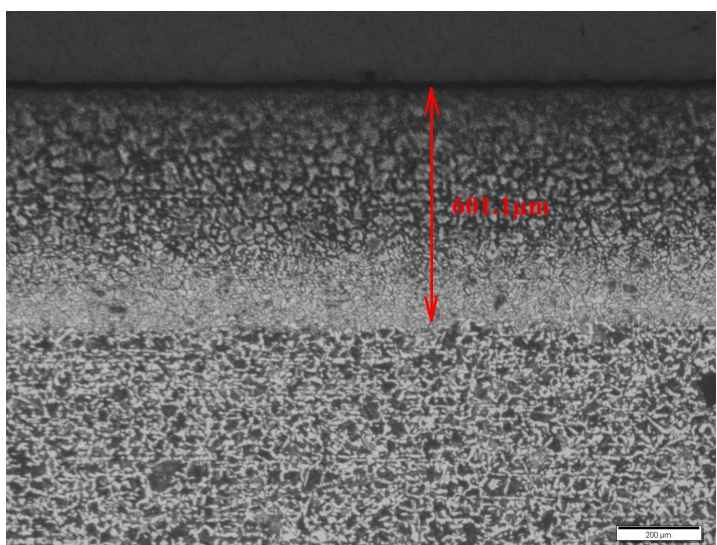

(a)

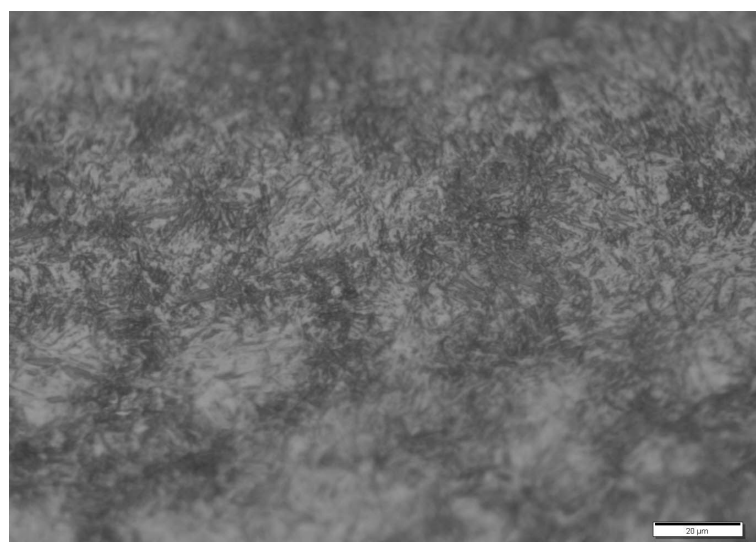

(b)

Fig.6 Metallographical micrograph of No.6 specimen

Except those same features, it can be seen that the others of the three grinding hardened layers have obvious differences and their metallographical microstructure appears some diversity because of applying different pre-stress though they have the same depth of cut, feeding speed and wheel speed. The proportion of each kind of microstructure of each group is different. The thicknesses of them also show diversities. Using the thickness-measuring software of metallographical microscope itself, the hardening layer's thickness of No.4 was measured as 456.66 $\mu$ m, No.5's was $337.98 \mu \mathrm{m}$, and No.6's was $601.14 \mu \mathrm{m}$.

Figure 7 shows the variation of the hardness and thickness of specimen with the increasing of pre-stress under the condition of PSHG. It can be obtained that the surface hardness and thickness of hardening layer of specimen both present the variation of big-small-big with the increasing of pre-stress.

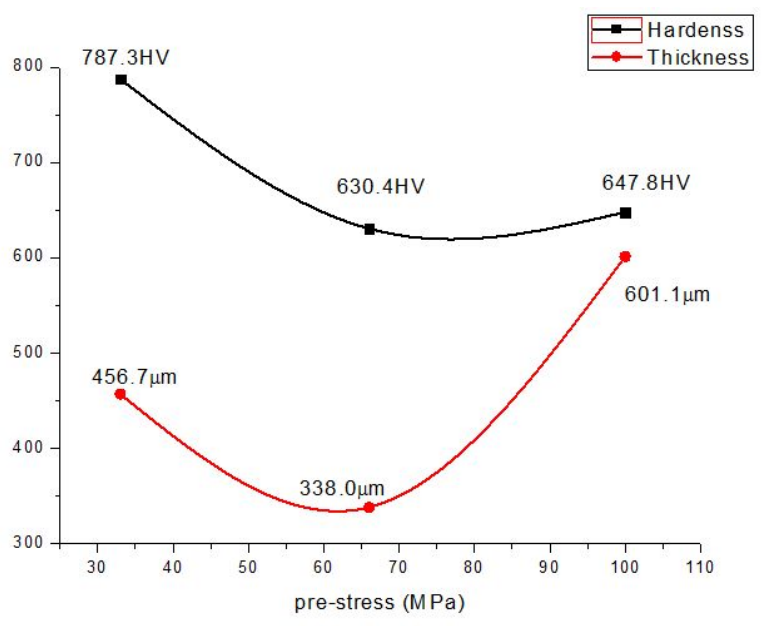

Fig.7 Variation of the hardness and thickness of specimen

\subsection{Wear Experiment and Analysis}

No.4, No.5 and No.6 specimen were put on wear tester to carry on wear experiment. Experiment conditions are shown in Table5.

Table 5 Wearing testing conditions

\begin{tabular}{llll}
\hline \hline Loading $(\mathrm{N})$ & Frequency $(\mathrm{Hz})$ & Moving distance $(\mathrm{mm})$ & Time $(\mathrm{min})$ \\
\hline 20 & 10 & 5 & 120 \\
\hline
\end{tabular}

And the testing results are shown in Table 6.

Figure 8 shows the variation of the wear loss of specimen. It can be seen that it has the variation of small-big-small with the increasing of pre-stress, which is opposite to the variation of hardness and thickness in Fig. 7. And its wearing resistance has the same variation as the hardness and thickness of hardening layer. That is the result of the phase transformation of different degrees due to different pre-stress. 
Table 6 Wear testing results

\begin{tabular}{|c|c|c|c|}
\hline No. & 4 & 5 & 6 \\
\hline Mass before test $(\mathrm{g})$ & 21.4904 & 18.3731 & 19.7137 \\
\hline Mass after test(g) & 21.4882 & 18.3684 & 19.7113 \\
\hline Depth of mill groove $(\mu \mathrm{m})$ & 46.830 & 54.435 & 39.705 \\
\hline Width of mill groove $(\mathrm{mm})$ & 2.0916 & 1.6908 & 1.6238 \\
\hline Abrasion loss $\left(\mathrm{mm}^{3}\right)$ & 0.1777 & 0.2485 & 0.1806 \\
\hline 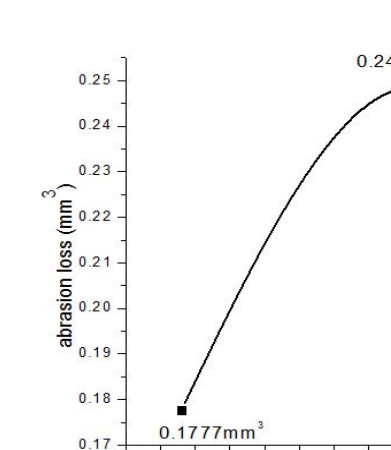 & & F-AAbr & sion loss \\
\hline \begin{tabular}{c|c}
1 & 1 \\
50 & 60 \\
& pre-s
\end{tabular} & $\begin{array}{ll}70 & 1 \\
70 & 80 \\
s(\mathrm{MPa})\end{array}$ & 100 & 10 \\
\hline
\end{tabular}

Fig.8 Variation of the wear loss of specimen

\section{Temperature field simulation of PSHG}

\subsection{Simulation Model}

The transformation of microstructure and the material properties of 45 steel have a close relationship with temperature. So an ANSYS temperature field simulation was done in the experiment condition with $200 \mu \mathrm{m}$ depth of cut (No.4, No.5 and No.6groups). The simulation result can be regarded as grinding temperature approximately.

The thermal properties are decided by grinding heat generated in the process. And the grinding heat is based on the contacting characteristic between abrasive grains and surface materials. Factors which affect it mainly consist of feeding speed, depth of cut and wheel speed. The pre-stress can't influence the contact between abrasive grains and surface materials. It can just influence the phase transformation. During the phase transformation, its latent heat has a very small order of magnitudes compared with the grinding heat (Mao, et al., 2014). So the pre-stress field has little effect on temperature field. The simple simulation result of temperature field can be regarded as the results of the one that applied different pre-stress.

The simulation took parabolic heat source model. The tangential grinding force $F_{t}$ of grinding wheel can be calculated by equation ( $\mathrm{Li}$ and Zhao, 2003):

$F_{t}=0.5 \times 28282 \times\left(a_{p}\right)^{0.86} v_{s}^{-1.06}\left(60 v_{w}\right)^{0.44}$

The heat-intensity $q_{t}$ in the grinding process is (Guo, et al., 1999):

$q_{t}=\frac{F_{t} v_{s}}{b l_{g}}$

The proportionality coefficient of grinding heat transmitted into specimen is

$$
R_{w}=\frac{1}{1+\sqrt{\frac{(\lambda \rho c)_{s}}{(\lambda \rho c)_{w}}}}(\text { Guo, et al., 1999) }
$$

which can be calculated as 0.82 according to the value of the experiment. So the heat-intensity $q_{w}$ transmitted into the specimen is:

$q_{w}=q_{t} R_{w}=0.82 q_{t}$

The main simulation parameters are listed in Table 7.

The simulation chose SOLID70 which is 3D thermal entity and has eight thermal DOF. The size of simulation 
specimen is $20 \mathrm{~mm} \times 22 \mathrm{~mm} \times 10 \mathrm{~mm}$. Take 4 times contacting arc length as the grinding simulation length. Meshing is shown in Fig. 9. There are $40 \times 30 \times 15$ meshing units.

Table 7 Simulation parameters setting

\begin{tabular}{cc}
\hline \hline Grinding factors & Parameter \\
\hline Diameter of grinding wheel $d_{s}(\mathrm{~mm})$ & 250 \\
Wheel speed $v_{s}(\mathrm{~m} / \mathrm{s})$ & 37.7 \\
Feeding speed $v_{w}(\mathrm{~m} / \mathrm{s})$ & 0.022 \\
Depth of cut $a_{p}(\mathrm{~mm})$ & 0.200 \\
Pre-stress $\sigma(\mathrm{MPa})$ & $33.3,66.7,100$ \\
Grinding width $b(\mathrm{~mm})$ & 10 \\
Contacting arc length $l_{g}(\mathrm{~mm})$ & 7 \\
\hline & \\
& \\
\hline
\end{tabular}

Fig.9 The Meshing figure of the model

\subsection{Simulation Result}

Equivalent heat source moves from one side of specimen to another in the grinding. Simulation result shows that the temperature of surface layer while grinding is close to $1100^{\circ} \mathrm{C}$. Fig. 10 is the cloud maps of temperature field of the $21^{\text {st }}$ loading. It is an instant during the grinding hardening. Now the temperature field has been stable and is typical. The two critical temperatures of 45 steel are $320{ }^{\circ} \mathrm{C}$ (martensite transformation temperature) and $720{ }^{\circ} \mathrm{C}$ (austenitic transformation temperature). It is obtained from Fig. 11 that the surface temperature can reach to the austenitic transformation temperature when grinding and also can reach martensite transformation temperature when cooling. It shows that the grinding hardening experiment of 45 steel has the basic condition of martensite transformation. However, microstructures of No.4, No.5 and No.6 groups have different thicknesses and different features under the same temperature field. It shows that different pre-stresses have an effect on phase transformation. 


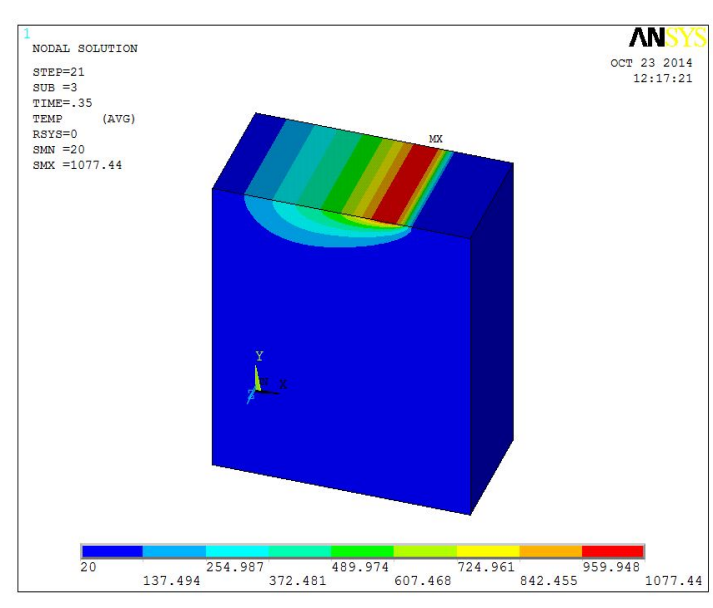

(a)

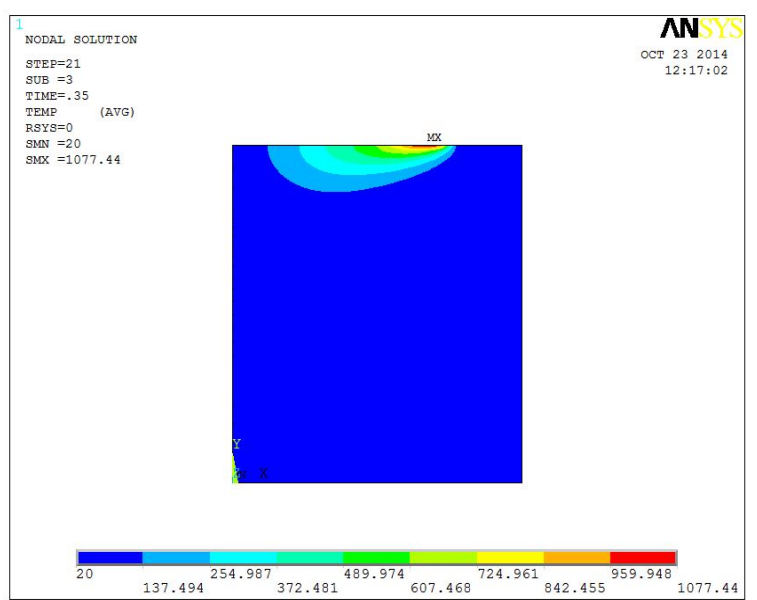

(b)

Fig.10 The cloud maps of thermal field of the $21^{\text {st }}$ loading

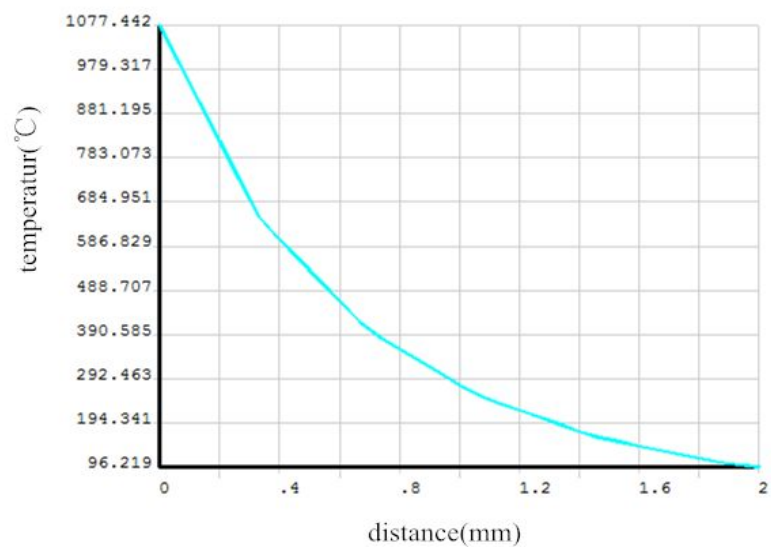

Fig.11 Temperature variation along with distance to the surface

\section{Transformation mechanism of Microstructure affected by pre-stress}

The hardness and wearing resistance and some other properties all have a relationship with the characteristic of microstructure. So the affecting mechanism of pre-stress to it will be analyzed in detail.

No.4, No.5 and No.6 specimen are taken as the main study objects which have good hardening effect. Grinding hardening is mainly composed of mechanical enhancement which is caused by the impacting of abrasive grains and quench hardening which is caused by thermal phase transformation. Because grinding parameters of No.4, No.5 and No.6 in the experiment are the same such as depth of cut, feeding speed and wheel speed, the mechanical enhancement condition caused by impacting and plastic deformation is the same. Therefore, the analyzing process can be simplified. The plastic deformation due to the impact of abrasive grains can be removed at the same time. And only phase transformation is analyzed which is affected by applying different pre-stress. The martensite transformation plays the main role in the hardening effect in all microstructure, so the effect of different pre-stress to the martensite transformation is analyzed chiefly.

The yield strength of 45 steel would be lower with the temperature rising as is shown in Table 8 (William and Javad, 2011). According to the simulation result of temperature field as Fig. 11, the temperature of grinding surface could reach $1000^{\circ} \mathrm{C}$ when depth of cut is $200 \mu \mathrm{m}$. Then the yield strength reduces to about $40 \mathrm{MPa}$ (William and Javad, 2011). According to Eq. (2), the pre-stress of No.4, No.5 and No.6specimens is $33 \mathrm{MPa}, 66 \mathrm{MPa}$ and $100 \mathrm{MPa}$ by turn. So No.4 specimen is in the state of elastic deformation, while No.5 and No.6 are in the state of plastic deformation.

When the pre-stress is $33 \mathrm{MPa}$, the material is in the state of elastic deformation after the effect of pre-stress. In the grinding process, the pre-stress would increase the free energy of martensite transformation. It will make the phase happen in advance. So in this state the pre-stress has promotion effect on martensite transformation. And it is in accordance with most researchers' result, which is widely accepted as "stress induces phase" phenomenon. It accords 
with Koistinen-Marburger martensite transformation dynamic model (Jin, 2009) (Grum, et al., 2008). Because this pre-tress is close to the yield strength, the promotion effect to phase transformation has reached a high level. So its hardness is big. In the metallographical figure, there is very large amount of martensite and it has dense texture. The whole thickness is large which is shown in Fig.4.

Table 8 Changes of some material properties with temperature of 45 steel

\begin{tabular}{cccc}
\hline \hline Temperature $\left({ }^{\circ} \mathrm{C}\right)$ & Elasticity modulus (GPa) & Yield strength (MPa) & Shear modulus (GPa) \\
\hline 100 & 200 & 330 & 80.4 \\
200 & 192 & 300 & 77.2 \\
300 & 184 & 262 & 74.8 \\
500 & 163 & 175 & 60.2 \\
800 & 125 & 60 & 30.6 \\
1000 & 99 & 40 & 14.7 \\
\hline
\end{tabular}

The pre-stresses of No.5 and No.6 are 66.7MPa and 100MPa respectively, which all surpass the yield strength of current temperature 40MPa. Material has plastic deformation under the stretching effect of pre-stress. During the process pre-stress increases the free energy of martensite transformation which is the same as elastic deformation. Besides, the pre-stress has two opposite effects on the martensite transformation. The positive effects of plastic transformation are like this (Grum, et al., 2008) (Liu, et al., 1999) (Leskovsek, et al., 2014) (Beese and Mohr, 2011): The boundary of grain changes into irregular waviness from smooth and regular shape after plastic deformation, thus many micro-areas with high boundary energy are easy to form in the grain boundary. Martensite transformation is easy to generate in these micro-areas. And the grains are stretched after plastic deformation, which also contributes to the nucleation of martensite. So plastic deformation would increase the forming speed of martensite in austenitic. Thus it increases the speed of martensite transformation. This is so-called "strain inducing phase transformation". While the negative effects are like this (Dominguez and Sevostianov, 2011) (Xiu, et al., 2009): plastic deformation will cause hardening in the surface materials. The martensite transformation is a shearing-type transformation. Large strengthening of parent phase would hinder the shearing process, which hinders the phase transformation equivalently. So it decreases the speed of phase transformation and parent phase is more stable. That is mechanical stability. The comprehensive result of the two functions is the final influence of pre-stress to martensite transformation.

The hardness of No.5 specimen is smaller than that of No.4. Its thickness of hardening layer is thin relatively and the density of martensite is small in metallographical figure, which is shown in Fig.5. It indicates that pre-stress has negative effect to martensite transformation during the beginning part of plastic deformation. During the process, the negative effect to martensite transformation which is caused by mechanical stability is larger than the positive effect which is caused by stretching grain.

And the hardness of No.6 specimen is larger than that of No.5again. And its hardening layer is thicker than that of No.5 in metallographical figure. The amount of martensite becomes larger. It indicates that pre-stress has positive effect to martensite transformation during the last state of plastic deformation. It can be observed from Fig. 6 that the grains have obvious stretching phenomenon. It shows that the stretching produces the area where martensite is easy to form. And this mechanism is at the leading position. So the pre-stress promotes the martensite transformation at this time.

\section{Analysis and variation mechanism of residual stress in PSHG}

Many studies and engineering experience show that the anti-fatigue property has a close relationship with the residual stress. Large tensile residual stress can produce fatigue crack and the workpiece runs out. On the contrary, if it can produce little tensile stress or even compressive residual stress, the anti-fatigue property would be improved. (Evans, et al., 2005) One of the most important meanings of PSHG is that it can reduce the residual stress of the surface of workpiece after grinding. So the characteristic of residual stress and its variation mechanism will be analyzed.

\subsection{Generation of Residual Stress in Grinding Process}

There are several main reasons of the generation of residual stress in hardening layer (Abdul Aziz, et al., 
2013)(Karabelchtchikova, et al., 2008) (Choi, 2009) (Duscha, et al., 2011) (Tönissen, et al., 2012). The final residual stress is the comprehensive result of these factors.

Residual stress due to mechanical effect. The surface material is impacted by abrasive grains in grinding process which has large strain rate and stress. Then materials of this area will have plastic deformation. After grinding it can't recover fully because crystal lattices of materials smash and have larger separation. The volume of surface materials is larger and then residual stress generates.

Residual stress due to heating effect. Surface layer of materials will have thermal expansion under the high temperature caused by grinding heat. But the temperature of inner layer changes little and has little expansion. So the thermal expansion of surface layer will be restricted by inner layer, and it has compressive stress. The stress is usually larger than the yield strength under the high temperature and surface material will have plastic deformation. When cooling down the cooling speed of surface layer is faster than the interior's. With the constriction of surface layer, tensile residual stress generates. This kind of residual stress usually occupies a high proportion in grinding residual stress.

Residual stress due to phase transformation. Different microstructure has different density and specific volume. And when microstructure with big specific volume transfers to the one with small specific volume, materials will have tensile residual stress. On the contrary it will have compressive residual stress. In grinding hardening, austenite transfers to martensite. So the process generates compressive residual stress.

In most instances of mechanical process, the first reason plays a main role and tensile residual stress reveals in the surface materials. It is harmful to the anti-fatigue property of wokpiece. (Choi, 2009) (Duscha, et al., 2011)

\subsection{Measurement of Residual Stress}

The residual stress of each specimen was measured using X-ray diffraction technique (XRD). It based on the theory of elastic mechanics and X-ray diffraction in crystals. The residual stress can change the distance of different crystal face and the direction of crystal face regularly. So the diffraction spectral line of X-ray moves. The residual stress can be calculated according to the moving distance of spectral line. The method has high measurement precision, and it is not easy to damage the surface of workpiece.

$\mathrm{X}$-ray diffraction technique measures the average stress value of one point and a small area around it. The cut-in, middle and cut-out areas of one workpiece are taken as the measurement location. Their locations are shown in Fig. 12. Their results are shown in Table 9.

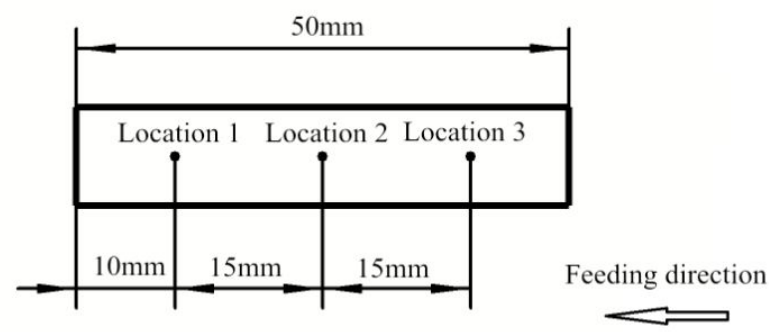

Fig. 12 Location of each measuring point

Table 9 Measuring result of residual stress (MPa)

\begin{tabular}{lllll}
\hline \hline No. & Location 1 & Location 2 & Location 3 & Average \\
\hline 1 & 589.3 & 563.2 & 480 & 544.2 \\
2 & 505.2 & 579.2 & 541.4 & 541.9 \\
3 & 467.7 & 508.7 & 432 & 469.5 \\
4 & -382.6 & -403.4 & 104.6 & -296.9 \\
5 & -177 & -22.6 & 119.8 & -26.6 \\
6 & -637 & -512.3 & -520.9 & -556.7 \\
\hline
\end{tabular}

Where, plus sign represents tensile residual stress and minus sign represents compressive residual stress. The average residual stresses of No.1, No.2 and No.3 show tensile residual stress. And the average residual stresses of No.4, No. 5 and No. 6 show compressive residual stress. In the Location 3 of No. 4 and No.5 specimens it shows partly tensile residual stress. The reason is like this: in the cut-in area, grinding heat has just begun to accumulate, and the temperature is low. So there isn't so much martensite in the area. (Martensite phase transformation can generate 
compressive residual stress.) Materials of Location 3 can emerge tensile residual stress because it is lack of martensite.

The ideal study target is the residual stress of the whole surface layer, so we choose the three points as the representatives and figure out their average values as the residual stress of one workpiece. The average value shows some laws and associations with other parameters as is shown in the paper.

\subsection{Analysis of Residual Stress}

The residual stress of No.1, No.2 and No.3 specimens are compared. Their variation is shown in Fig. 13. Their depths of cut are the same which is $50 \mu \mathrm{m}$. And their pre-stresses are $33 \mathrm{MPa}, 66 \mathrm{MPa}$ and $100 \mathrm{MPa}$. There is little hardening effect within the surface layer. It can be seen that the larger the pre-stress is, the smaller the tensile residual stress. This is because the pre-stress can stretch both the surface and the inner layer of hardening layer in the scope of elastic deformation in the grinding condition. According to the analysis in Chapter Residual stress due to mechanical effect, surface layer has plastic deformation due to the impact of abrasive grains and grinding heat which can't restore. But the inner layer just has elastic deformation due to the pre-stress and it can restore after pre-stress is unloaded. Then the constraint effect to the surface will cause compressive residual stress within it to counteract the tensile residual stress which is caused by heating effect. At last its comprehensive result shows a smaller tensile residual stress. And the bigger the pre-stress is, the larger the compressive residual stress it causes, and the smaller the residual tensile stress it reveals at last. In this situation the pre-stress affects the residual stress in a direct way relatively.

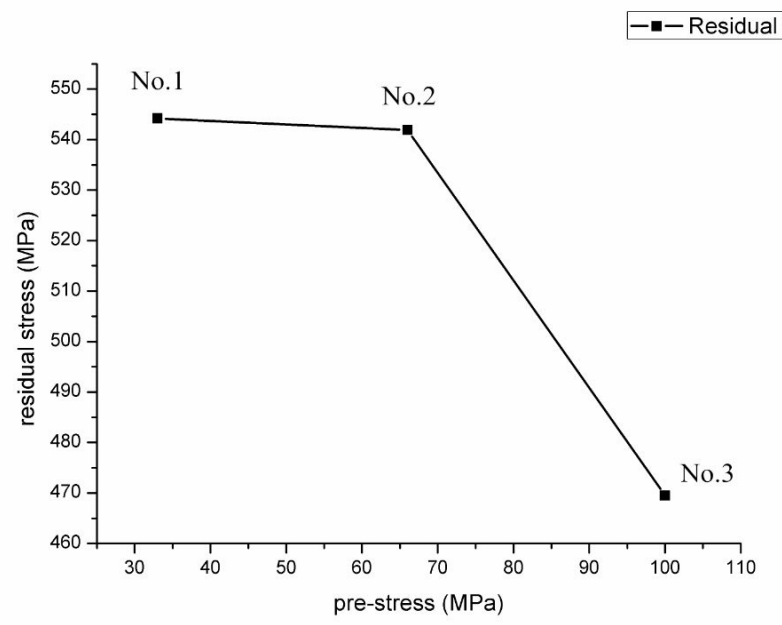

Fig.13Variaton of residual stress with the increasing of pre-stress of No.1, No.2 and No.3 specimens

The residual stress of No.1 and No.4 specimens are compared. It has the same pre-stress which is $33 \mathrm{MPa}$ and different depth of cut. It can be seen that the residual tensile tress transfers to compressive residual stress with the increasing of depth of cut from $50 \mu \mathrm{m}$ to $200 \mu \mathrm{m}$. This is because the deeper depth of cut causes grinding hardening and the martensite transformation causes compressive residual stress according to the analysis of Chapter Residual stress due to phase transformation. Moreover the hardening effect plays a leading role in the factors which influence residual stress. So the larger depth of cut can reduce tensile residual stress or generate compressive residual stress. The same result can be obtained compared with No. 2 and No.5 or No.3 and No.6.

The residual stress of No.4, No.5 and No.6 specimens are compared. Their variation is shown in Fig.14. All their depths of cut are $200 \mu$ mwhich is larger than the ones of No.1, No.2 and No.3. And their pre-stresses are $33 \mathrm{MPa}$, $66 \mathrm{MPa}$ and 100MPa respectively. The situation belongs to the PSHG. It can be seen that their compressive residual stresses have the variation of big-small-big with the increasing of pre-stress. The influence of pre-stress to the residual stress is different from the results of No.1, No.2 and No.3 obviously. This is because that different pre-stress has different influence on the phase transformation according to the analysis of Chapter 4.1. With the increasing of pre-stress the phase transformation has the variation from big-small-big. And phase transformation plays a leading role in affecting residual stress in this grinding condition. So the compressive residual stress has the same variation as the phase transformation. And in this situation, the pre-stress affects the residual stress in an indirect way. It affects the residual stress through affecting phase transformation. 


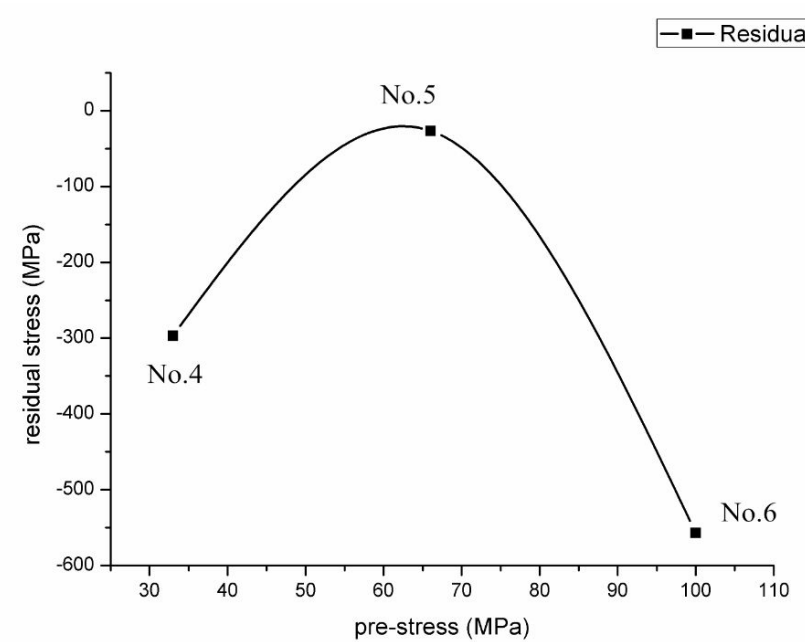

Fig.14Variation of residual stress with the increasing of pre-stress of No.4, No.5 and No.6 specimen

It can be concluded from the experiment result that the PSHG experiment gains the surface hardening layer with smaller tensile residual stress or compressive residual stress, and it will have good working performance. By adjusting the pre-stress the residual stress can be controlled in the grinding with both large depth of cut (PSHG) and small depth of cut. And the pre-stress has two different affecting mechanism to the residual stress.

\section{Conclusions}

The PSHG experiment obtains the surface hardening layer with smaller tensile residual stress or compressive residual stress which has good working performance. Through applying different pre-stress onto the workpiece, PSHG realizes the residual controlling compared with GH. And it can produce different hardening effect compared with PSG.

Under the condition of PSHG, the surface hardness, thickness of hardening layer and the abrasive resistance of specimen all reveal the variation of big-small-big with the increasing of pre-stress. The property of hardening layer can be controlled by applying different pre-stress.

Under the condition of PSHG, during the initial stage of plastic deformation due to pre-stress, parent-phase-strengthening plays a main role and pre-stress has inhibiting effect on martensite transformation. In the later stage of plastic deformation due to pre-stress, the stretching of grain boundary contributes to the formation of martensite. "Strain inducing phase transformation" plays a main role. The pre-stress promotes martensite transformation.

Pre-stress has two different affecting mechanism to the residual stress in the experiment. In PSHG, pre-stress affects the residual stress mainly through affecting phase transformation. The compressive residual stress has the variation of big-small-big with the increasing of pre-stress.

\section{Acknowledgements}

This project is supported by National Natural Science Foundation of China (Grant No. 51375083), Technology Project of Shenyang City (Grant No. F13-316-1-59) and the Fundamental Research Funds for the Central Universities of China (Grant No. N140306002).

\section{References}

Abdul Aziz, M.S., Furumoto, T., Kuriyama, K., Takago, S., Abe, S., Hosokawa, A., Ueda, T., Residual Stress and Deformation of Consolidated Structure Obtained by Layered Manufacturing Process, Journal of Advanced Mechanical Design, Systems, and Manufacturing, Vol.7, No.2 (2013), pp. 244-256.

Beese, A.M. and Mohr, D., Effect of Stress Triaxiality and Lode Angle on the Kinetics of Strain-induced Austenite-to-mantensite Transformation, ACTA MATERIALIA, Vol.59, No.7 (2011), pp. 2589-2600. 
Brinksmeier, E. and Brockhoff, T.,Surface heat treatment by using advanced grinding processes,La Metallurgia Italiana, Vol.91, No.4(1999), pp. 19-23.

Choi, Y., A comparative study of residual stress distribution induced by hard machining versus grinding, Tribology Letters, Vol.3, No.36 (2009), pp. 277-284.

Dominguez, D. and Sevostianov, I., Cross-property Connection between Work-hardening Coefficient and Electrical Resistivity of Stainless Steel during Plastic Deformation, International Journal of Fracture, Vol.167, No.2 (2011), pp. 282-287.

Duscha, M., Klocke, F., Wegner, H., Residual stress model for speed-stroke grinding of hardened steel with CBN grinding wheels, International Journal of Automation Technology, Vol.3, No.5 (2011), pp. 439-444.

Evans, A., Kim, S.B., Shackleton, J., Bruno, G., Preuss, M., Withers, P.J., Relaxation of residual stress in shot peened Udimet 720 Li under high temperature isothermal fatigue, International Journal of Fatigue, Vol.27, No.10-12 (2005), pp. 1530-1534.

Grum, J., Kek, T., Zupancic, M., Batista, M., Kosef, F., Measurement and numerical analysis of surface residualstresses occurring under different quenching conditions, International Journal of Microstructure and Materials Properties, Vol.3, No.1(2008), pp. 86-99.

Guo, C., Wu, Y., Varghese, V., Malkin, S., Temperatures and energypartition for grinding with vitrified CBN wheels, Annals of the CIRP, Vol.48, No.1(1999), pp. 247-250.

Jin, J.L., Dynamic research method of TEM and SEM on stress induced phase transformation, Shanghai Metals, Vol.22, No.5 (2009), pp. 39-44.

Karabelchtchikova, O., Rivero,I.V., Hsiang, S.M. Model of residual stress distribution in D2 steel via grinding dynamics using a second-order damping system,Journal of Materials Processing Technology, Vol.1-3, No.198(2008), pp. 313-322.

Leskovsek, V.,Godec, M., Kogej, P., Strengthening via the Formation of Strain-induced Martensite and the Effects of Laser Marking on the Microstructure of Austenitic Stainless steel, Metallurgical and Materials Transactions A-Physical Metallurgy and Materials Science, Vol.45A, No.6 (2014), pp. 2819-2826.

Li, B. and Zhao, B., Modern grinding technology (2003) China Machine Press., Beijing.

Liu,C.C., Yao,K.F., Gao,G.F., Liu, Z., Study to the effect of stress and strain on Martensite transformation kinetics and transformation plasticity, Acta Metallurgica Sinica, Vol.35, No.11 (1999), pp. 1125-1129.

Liu, J.D., Wang, G.C., Wang, Z., Fan, S.T., Experimental Research on Grind-Hardening of 65Mn Steel, Materials Science Forum, Vol.505-507, No.2(2006), pp. 787-791.

Mao, L.B., Liang, Z.B., Lin, J.T., Li, F.T., Kong, X.Z., Jia, D., Phase change emulsions for latent heat transportation: Preparation and characterization, Energy Storage Science and Technology, Vol.3, No.2(2014), pp. 47-51.

Menenzes,P., Kallas, S., Lovell, M., Role of surface texture,roughnessand hardness on friction during unidirectional sliding,Tribology Letters, Vol.41, No.1 (2011), pp.1-15.

Slowinski, B., Nadolny, K., Effective Manufacturing Method for Automated Inside Diameter Grinding, Journal of Advanced Mechanical Design, Systems, and Manufacturing, Vol.1, No.4 (2007), pp. 472-480.

Tönissen, S., Klocke,F., Feldhaus, B., Buchholz, S., Weiss, M., Residual stress prediction in quick point grinding, Production Engineering, Vol.3, No.6 (2012), pp. 243-249.

William, F.S. andJavad, H., Foundations of Materials Science and Engineering (2011) China Machine Press., Beijing.

Xiu, S.C., Li, C.H., Cai, G.Q., Study on surface finish mechanismin quick-point grinding, Int Journal of ComputerApplications in Technology, Vol.29, No.2(2007), pp. 163-167.

Xiu, S.C., Yuan,S.X., Cai,G.Q., Researches on effect of impact micro-damages in contract layer on machinability in quick-point grinding, Key Engineering Matrerials, No.389-390 (2009), pp. 229-234.

Ye, B.Y., Peng, R.T., Tang, X.Z., Liang, Z.W.,Residual stress and surface morphology of pre-stress hard cutting,Journal of South China University of Technology, Vol.36, No.4 (2008), pp. 6-9.

Zhang, L., Ge, P.Q., Zhang, J.H., Experiment and simulation on temperature field of $40 \mathrm{Cr}$ steel surface layer ingrind-hardening,Intemational Joumal of Abrasive Technology, Vol.1, No.2, (2007), pp. 187-197. 